\title{
NATIONAL RECOVERY AND RESILIENCE PLAN EUROPEAN FUNDS MULTIPLIER ROLE AND POSSIBILITIES OF MINISTRY OF NATIONAL DEFENCE INVOLVEMENT IN THE PROCESS
}

\author{
Dumitru Nica ${ }^{1}$ \\ "Carol I" National Defence University \\ Carmen-Gabriela Nitu (Chitafes) \\ "Carol I" National Defence University
}

\begin{abstract}
This paper aims at expressing the manner in which the Ministry of National Defence (MoND) can benefit from direct support, efficient and significant financial support for the implementation of sustainable reforms and public investments, as provided in the National Recovery and Resilience Plan (NRRP). The situation triggered by COVID-19 brings about new awareness in Romania and among all the EU member states, through the economic-financial crisis, jobs crisis, health, education, research, innovation and digitalization crisis, which has an impact on the drop of revenues both at European and international level. We must agree that such pandemics should find us prepared and that the investments should be planned well beforehand, similarly to the creation of an army. The defence of a state requires costs, and the financial support allocated to the defence sector is visible in the results of the foreign and economic policy of Romania. From this perspective, the MoND has prepared a series of proposals included in a number of reforms and investments documents. Such reforms and investments are absolutely necessary to Romania and represent essential contributions to the NRRP.
\end{abstract}

Keywords: recovery and resilience facility; reform; investments; European funds.

\section{INTRODUCTION}

The world is constantly changing, and the crisis triggered by COVID-19 has modified the economic, social and budgetary perspectives and led the European Commission, the European Parliament and the European Union (EU) leaders to agree on a Recovery and Resilience Plan, to support and help also our country lead the way out of the crisis and lay the foundations for a modern and sustainable Europe, as to contribute to the repair of the economic and social damages caused by COVID-19 (European Commission 2021).

The European Union has decided to establish a "temporary financial instrument \#NextGenerationEU, amounting to 750 billion euro, separated from the EU's long-term budget, the Multiannual Financial Framework (MFF), for the period 2021 -2027. Its main purpose is to provide support to the member states to face the challenges of the COVID-19 crisis and its economic consequences. The recovery and resilience facility (RRF) is the main pillar of \#NextGenerationEU and has total allocated budget of 672.5 billion euro (European Commission 2021)". The budget of this instrument, RRF, consists of: "A. Grants amounting to up to 312.5 billion euro; B. Loans amounting to up to 360 billion euro (Ministry of Investment and European Projects 2021)".

In this context, the current framework has to be strengthened and to provide direct financial support to the member states, including Romanian, by means of an "innovating" instrument. Thus, a Recovery and Resilience Facility (RRF) has been established to provide efficient and significant support, having the multiplier role to accelerate the implementation of the sustainable reforms and

\footnotetext{
${ }^{1}$ Corresponding author: nicadumitru_aism@yahoo.com
} 
public investments. RRF is conceived on another basis, with an approach different from the management of the cohesion funds, i.e. on a sectorial logic. The aim of this instrument is to provide financial support to the member states, in order to ensure fast economic recovery.

"To ensure that the financial support is frontloaded in the initial years after the COVID-19 crisis, and to ensure compatibility with the available funding for the Facility, the funds should be made available until 31 December 2023. To that end, it should be possible for $70 \%$ of the amount available for non-repayable financial support to be legally committed by 31 December 2022 and $30 \%$ between 1 January 2023 and 31 December 2023 (Official Journal of the European Union 2021)".

Moreover, all payments for the projects to be included in the NRRP must be made until 31 December 2026.

Starting from this aspect, we have built up this approach since we have identified in this scope of the facility the fact that it refers to "policy areas of European relevance structured in six pillars (the 'six pillars'), namely: green transition; digital transformation; smart, sustainable and inclusive growth, including economic cohesion, jobs, productivity, competitiveness, research, development and innovation, and a well-functioning internal market with strong small and medium enterprises (SMEs); social and territorial cohesion; health, and economic, social and institutional resilience with the aim of, inter alia, increasing crisis preparedness and crisis response capacity; and policies for the next generation, children and the youth, such as education and skills (Official Journal of the European Union 2021)".

Besides, both at European and national level, integrated knowledge and education management digitalization in the military education institution has been a constant preoccupation in recent years, but the COVID-19 crisis revealed the vulnerabilities of the system and brought forward the necessity to accelerate this process.

\section{ROLE, IMPORTANCE AND CURRENT STATUS OF THE NATIONAL RECOVERY AND RESILIENCE PLAN}

The member states, including Romania, have prepared the recovery and resilience plans establishing a package of reforms and public investments. The Romanian state, in order to benefit from EU support, has to meet the condition for the reforms and investments indicated in the NRRP to be implemented until 2026.

We consider that the proposed NRRP has to efficiently detail the challenges in the European Semester 2020, particularly those in the Country Report (European Commission n.d.), which formulates a series of specific recommendations for each country.

"NRRP is Romania's strategic document providing for the reform priorities and investments sectors at national level for the establishment of the RRF. The funding source is the funds allocated to Romania under the Recovery and Resilience Facility (RRF) and, additionally resources allocated from the state budget. The end purpose of the NRRP is to improve the situation of the national economy after the COVID-19 crisis, as well as to ensure the economic growth and creation of jobs required for the inclusion of disadvantage groups, support the green and digital transition to promote sustainable development (Romanian Government 2020)".

At this moment, NRRP is being largely updated, according to the provision and calendar indicated in the Memorandum "Mechanism for the elaboration of the position of the Government of Romania as concerns the National Recovery and Resilience Plan", approved in the Government meeting on 20 January 2021.

We can notice that the updated NRRP gathers about 30 components, classified under six distinct pillars, according to the requirements of the REGULATION (EU) 2021/241 OF THE EUROPEAN PARLIAMENT AND OF THE COUNCIL of 12 February 2021 establishing the Recovery and Resilience Facility, i.e.: Pillar I: Transition to a green economy; Pillar II: Digital transformation; Pillar III: Intelligent, sustainable and inclusive growth; Pillar IV: Social and territorial cohesion; Pillar V: Health and economic, social and institutional resilience; Pillar VI: Policies for the next generation, children and youth. 
In this phase, the Reforms and Investments Documents are collected from the specialized ministries and institutions in charge, including from the MoND, which are to be analyzed at the level of the MIEP to be included in the NRRP. At the same time, the MoND has to take into consideration that the projects proposed to be funded under NRRP must be mature project, an essential element being the commitment for them to be implemented and completed by 31 August 2026.

Thus, NRRP does not rely on project proposals, but is built on reforms undertaken by the specialized ministries, associated to investment measures evenly covering the 6 pillars agreed at European level, aiming at creating significant and long-term changes in remedying the challenges indicated in the Specific Country Reports, as to respond to the structural and stringent issues at national level.

With reference to the maximum allocations negotiated at the level of Romania, the public communication of the position paper "Update of the National Recovery and Resilience Plan" presented on 9 March 2021, in the European Affairs Committee of the Romanian Parliament, indicates that the recovery and resilience plans shall be approved within the budgetary framework negotiated and allocated for each member state, taking into consideration a minimum allocation of $37 \%$ to the achievement of climate objectives and $20 \%$ allocation for digitalization objectives. The RRF Regulation specifies that the national plans should address a series of country specific recommendations, as they are mentioned in the European Semester reports. These recommendations are expected to be addressed through a series of reforms and investments, that each member state will propose within its national plan.

Romania has an allocated budget of 29.2 billion euro, which should be directed towards strengthening the economic growth potential, the creation of jobs and the economic and social resilience. Some of the reforms proposed refer to: a sustainable pensions system, a fair public salary system, a reform of the public administration, the reform of the state-owned companies (Ministry of Investment and European Projects 2021).

Thus, Romania is interested, in the first place, until the due date, for the submission of the NRRP, in sending interim projects to the Commission, with reforms and investments in the following intervention areas: Transport; Environment, climate change, energy, energy efficiency and green transition; Development of urban localities, valorisation of the natural and cultural heritage and tourism; Agriculture and rural development; Resilience in crisis situations; Health; Education; Business environment; Research, innovation, digitalization; Improvement of buildings. (General Government Secretariat 2021)"

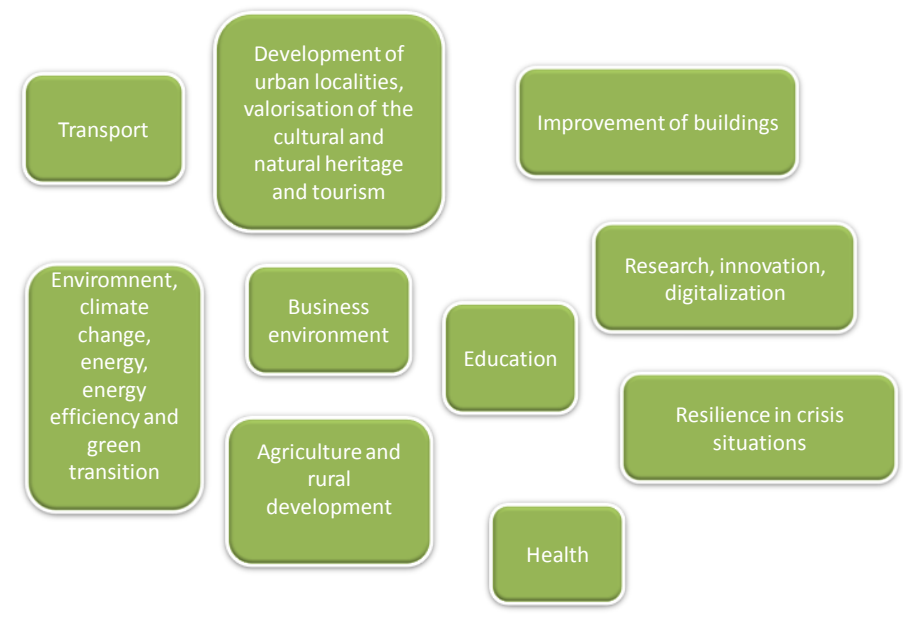

Figure 1. Types of intervention areas

We can underline that, at internal level, MIEP will propose for the Government to issue a decision containing as annexes the summary of each component (description of the current situation, 
proposed reforms and investments, necessary budget), which is to become a mandate for the negotiations with the European Commission.

Therefore, before 30 April 2021, which is the due date for the official submission of the document to the European Commission, all the specific procedures for the political commitments and approval of the NRRP are to be completed. In its turn, the European Commission analyzes the NRRP based on transparent means and criteria.

\section{POSSIBILITIES FOR THE INVOLVEMENT OF THE MOND IN THE PROCESS OF IMPLEMENTATION OF SUSTAINABLE REFORMS AND PUBLIC INVESTMENTS ACCORDING TO THE REQUIREMENTS OF THE NATIONAL RECOVERY AND RESILIENCE PLAN}

The update of the NRRP aims at including the contribution of all the stakeholders involved in the identification, drafting and formulation of reforms and investments documents, targeting the reforming of the most relevant sectors in our country, such as the importance of green transition, digital transformation, intelligent, sustainable and inclusive growth, health and economic, social and institutional resilience, as well as policies for the next generation, children and youth.

In this context, the Ministry of Investments and European Projects (MIEP) has started the entire process of elaborating the NRPP document ever since October-November 2020, when an initial version was created.

During that period, the coordinators and members of the technical working groups at the level of each sector covered by NRRP worked based on the templates and in the format required by the European Commission in September 2020, according to the final Proposal of Regulation of the European Parliament and of the Council for the establishment of the Recovery and Resilience Facility COM (2020) 408 and to the Guidelines for the completion of the NRRP, i.e. the criteria valid at that moment were complied with.

After the elaboration of the initial version of the NRRP, in November-December 2020 the first technical discussions with the representatives of the European Commission took place.

This is why, between 25 January - 23 February 2021, MIEP organized inter-ministerial consultations, in two rounds, as daily thematic discussion, to which participated the representatives of the specialized ministries in charge, involving also representatives of MoND, in each of the 10 working groups established per specific sectors. Representatives of the private sector and of the civil society, as well as academics participated to the second round, being invited to intervene in the debates and propose punctual contributions to be added in the Reform and Investments Documents. Thus, several public thematic debates were organized in February 2021, broadcast online, with partners in the business environment, NGOs and all the stakeholders in updating the NRRP.

Therefore, the updated version of the NRRP is drafted to comply with all the criteria required in the Regulation (EU) 2021/241 OF THE EUROPEAN PARLIAMENT AND OF THE COUNCIL of 12 February 2021 establishing the Recovery and Resilience Facility. The transparency of the topics under this approach was implicitly provided for during the meetings at the level of the MIEP, as well as through the public communication of the position paper "Update of the National Recovery and Resilience Plan" presented on 9 March 2021, in the European Affairs Committee of the Romanian Parliament.

In this context, in the next period the teams in charge at MIEP and at the ministries and institutions involved in the implementation of the reforms and investments proposed through the NRRP will participate actively to informal technical discussions with the representatives of the European Commission, as to agree on the detailed presentation of each component and to fit them in the format indicated in the Commission Guidelines.

"At this stage MIEP has decided to elaborate the first version of NRRP to be discussed with the European Commission. It was decided that the proposals sent to the European Commission to exceed the initial allocation (our estimation is $135 \%$ of the allocation), in order to have a margin for negotiation. This is also a decision taken by other countries that have submitted their first versions, 
exceeding the maximum allocation. As such, Croatia proposed an over-allocation of $240 \%$, Greece $141 \%$, the Czech Republic 125\%, Germany 124\%, Hungary 108\% and Italy 107\%. Therefore, this is not an exclusive decision of the Romanian government. All these decisions are assumed by the respective governments, considering that certain components can be over-estimated in terms of costs and other will be eliminated during the negotiations with the European Commission (Ministry of Investment and European Projects 2021)".

As you have noticed, even if states allocate more and more resources to the military, the real threat sometimes arises from other sectors of human activity, an unpredictable enemy, COVID-19. A very important role in the consolidation of the defence capabilities is strictly connected to the human resource and to the critical infrastructures preventing and mitigating the negative effects of phenomena that threaten the security of people.

The novelty of this communication is that MoND, may benefit from direct support for the implementation of sustainable reforms and public investments, as indicated in the NRRP.

The pillars of the development of the military structure are built by strengthening the human resource, modernizing the educational system, as a central element of the performance of such resource.

The following action roadmaps are of major importance for drafting projects involving entities in the Romanian army in NRRP: a) training the human resource in jobs and skills useful both for military activities in the civil life, when professional military leave the system; 2) modernizing the educational management and better digitalization of the military education institutions involved at all stages of training the military and civilians in the system; 3) rethinking the organization and modernization of the military hospitals infrastructure to counter any medical challenges and threats (as has been the case for the Coronavirus pandemic).

\section{CONCLUSIONS}

Strengthening the defence capabilities should also address to the human resources aspects along with the enforcement measures such as investments in infrastructure, equipment etc. The NRRP proposed by Romania has also included MoND, among the beneficiaries that may benefit from funding within NRRP, with a focus on increasing the competencies of the human resources in the military educational system.

As can be easily noticed, the support for the military education can be applied at two levels, one being the infrastructure in the military education institutions, that should rely on an integrated knowledge and education management digitalized system, and the other being the training and career management programmes, and respectively the management of qualifications and skills in developing both the military and civilian professional careers needed by and useful to MoND.

The military education is an essential component, a proof in this respect being the contribution to the elaboration of the NRRP, aiming in the first place at improving the military education system, as well as the training and qualification of the human resources in the military system.

To all these elements related to the human resource and to its better training for the army adds the rethinking of the organization and the modernization of the military hospitals infrastructure, as to counter any medical challenges and threats that may occur unexpectedly.

\section{REFERENCES}

European Commission. European Semester: assessment of progress on structural reforms, prevention and correction of macroeconomic imbalances, and results of in-depth reviews under Regulation. 2011. (EU) no. 1176/. n.d. https://ec.europa.eu/info/sites/info/files/2020-european_ semester_country-report-romania_ro.pdf, accessed 03 10, 2021.

The European Resilience Plan. 2021. https://ec.europa.eu/info/strategy/recovery-plan-europe_ro, accessed 02 07, 2021. 
The Recovery and Resilience Facility. 2021. https://ec.europa.eu/info/business-economyeuro/recovery-coronavirus/recovery-and-resilience-facility_ro, accessed 03 03, 2021.

General Government Secretariat. 2021. "Memorandum on: The mechanism for elaborating the position of the Romanian Government regarding the National Plan of Recovery and Resilience“. gov.ro, https://sgg.gov.ro/new/wp-content/uploads/2021/01/MEMO-11.pdf, accessed 03 07, 2021.

Ministry of Investment and European Projects. Care sunt regulile cerute de Comisia Europeană și ce tipuri de proiecte se finanțează. 2021. https://mfe.gov.ro/10-care-sunt-regulile-cerute-decomisie-pentru-intocmirea-pnrr/, accesat 03 07, 2021.

National Recovery and Resilience Plan. 2021. http://mfe.gov.ro/pnrr/\#30, accessed 03 10, 2021.

Update of the National Recovery and Resilience Plan. 2021. Position Paper, presentation to the Parliament, https://mfe.gov.ro/wp-content/uploads/2021/03/6fbe88578f749fe3d28251dbf57 e4544.pdf, accessed 03 06, 2021.

Official Journal of the European Union. 2021. REGULATION (EU) 2021/241 OF THE EUROPEAN PARLIAMENT AND OF THE COUNCIL, https://eur-lex.europa.eu/legal-content/RO/ TXT/PDF/?uri=CELEX:32021R0241\&from=EN, accessed 03 05, 2021).

Official Journal of the European Union. REGULATION (EU) 2021/241 OF THE EUROPEAN PARLIAMENT AND OF THE COUNCIL. 2021, https://eur-lex.europa.eu/legalcontent/RO/TXT/PDF/?uri=CELEX:32021R0241\&from=EN, accessed 03 05, 2021.

Romanian Government. 2020. „Emergency Ordinance no. 155 concerning several measures to elaborate the Recovery and Resilience Plan required for Romania to access reimbursable and non-reimbursable external funds under the Recovery and Resilience Facility." Official Journal Of Romania no. 819. 